\title{
Sensitivity Analysis and Parameter Optimization of a Heat Loss Model for a Composting System
}

\author{
A. Mudhoo* and R. Mohee \\ Department of Chemical and Environmental Engineering, Faculty of Engineering, University of Mauritius, Réduit, Mauritius
}

\begin{abstract}
A combined multi-parameter sensitivity analysis/frequency array analysis technique was employed to assess the impact of design conditions and matrix-specific properties on the rate of heat loss from a self-heating composting process. This method was specifically used to identify the range of parameters over which a model predicting the overall heat-transfer coefficients $(U$-values) for the heat loss process are particularly sensitive. The model was found to be most sensitive for the following range of input parameters: the internal diameter of reactor varying from $0.8 \mathrm{~m}$ to $1.2 \mathrm{~m}$, the combined reactor wall and insulation thickness ranging from $4 \mathrm{~cm}$ to $6 \mathrm{~cm}$, the free airspace of the matrix varying from $50 \%$ to $60 \%$, the reactor length varying from $1.0 \mathrm{~m}$ to $1.5 \mathrm{~m}$, the thermal conductivity of the organic substrates ranging from $0.1 \mathrm{~W} / \mathrm{m} . \mathrm{K}$ to $0.2 \mathrm{~W} / \mathrm{m} . \mathrm{K}$ and the preferred thermal conductivity of the insulation material being less than $0.2 \mathrm{~W} / \mathrm{m} . \mathrm{K}$. A second sensitivity analysis was performed to identify which input parameters actually influenced the model's response the most. This analysis compared the acceptable and unacceptable frequency distributions of each input parameter, with model outputs below a $U$-value of $4.5 \mathrm{~W} / \mathrm{m}^{2} . \mathrm{K}$ being an acceptable composting performance from a thermodynamics consideration. This analysis disclosed the matrix free airspace, the internal diameter of the reactor and the combined thickness of reactor wall and insulation as the most important parameters which should be given high priority when designing invessel compost reactors.
\end{abstract}

Keywords: composting performance, multi-parameter sensitivity analysis, overall heat-transfer coefficients, reactors

\section{Introduction}

The self-heating composting process involves the biodegradation of the organic fraction (Haug, 1993; Komilis, 2004) of biodegradable wastes with the generation and release of metabolic heat from the compost matrix to the immediate surroundings across the reactor walls. Depending on the specific reactor design in terms of the material of construction of the reactor (Hogan et al., 1989), the mode of aeration (Sartaj et al., 1997), the type of material and thickness of insulation used (Hogan et al., 1989) and the structure of the compost matrix, the various heat transfer mechanisms (Mason and Milke, 2005) compete and contribute to the heat-loss processes. The net heat loss rate determines the overall temperature of the system (Nielsen and Berthelsen, 2002). The combined conductive/convective/radiative heat loss mechanisms (Mason and Milke, 2005) can be characterized and monitored by following the variation of the overall heat-transfer coefficient ( $U$-value) (Petiot and de Guardia, 2004) for such a system. Mathematical equations have been proposed to predict the $U$-values developed during the composting of a mixture of organic biodegradable wastes. The model developed from an energy balance was relatively simpler in terms of the number of parameters whereas the mathematical equation (thermal resistance pathway model) developed from a fluid flow theory approach consisted of a larger number of physical and ther-

\footnotetext{
* Corresponding author: ackmezchem@yahoo.co.uk
}

modynamic parameters difficult to quantify in practice. While it is believed that the set of data compiled in the derivation of model represents a preliminary but comprehensive analysis of the heat transfer resistance terms in invessel composting, it is also recognized that, in practice, process operating conditions will differ from those for which the model was specifically developed. Effective applications of the model to these alternative conditions will depend upon the confidence with which the parameters can be estimated and on the overall robustness of the model. The notion of robustness in biological systems has received considerable interest recently by experiments and in theoretical study of models (Tian, 2004). By saying that a system is robust it is implied that a particular function, response or predictive characteristic of the system is preserved within reasonably small margins of error despite changes in the operating environment. One fundamental parameter in the analysis of the robustness of the mathematical models is the model's sensitivity to parameter variations (Choi et al., 1999; Tian, 2004). These variations may be errors in parameter estimation or changes in the components of biological systems. This topic has been studied using numerous sensitivity analysis techniques ranging from methods involving partial differentiation to more elaborate procedures using Hessian matrices by Helton and Iman (1982), Turanyi (1990), Rabinowitz and Steinberg (1991), Hamby (1994), Saltelli et al. (2000), Fennel et al. (2001), Tian (2004) and Ravalico et al. (2005).

The composting process has been extensively studied and numerous mathematical models have been developed to de- 
scribe the heat dynamics and heat loss mechanisms by Hogan et al. (1989), Stombaugh and Nokes (1996), VanderGheynst et al. (1997), Mohee et al. (1998), Bari et al. (2000), Vining (2002), Ekinci et al. (2004a), Xi et al. (2005) and Ghaly et al. (2006). However, no data on a combined sensitivity analysis and optimization of numerous parameters involved in these models has been explicitly reported in compost literature. Hence, the objective of this study was to assess the sensitivity of a corrected form of the Thermal Resistance Pathway (TRP) model to the input parameters over a range of values that have been observed in practice for various composts. A combined multi-parameter sensitivity analysis (MPSA) and frequency array/frequency analysis technique has been used and a preliminary parameter optimization has also been conducted. The end results are intended to assist in the redesign of a compost bioreactor that could prolong the duration of the thermophilic temperatures within the matrix, and hopefully improve the biodegradation rates during the initial stages of the composting process.

\section{TRP-Model Description}

The TRP-model has been developed by considering three physical processes for heat flow in the radial direction. The heat generated within the inner core of the matrix is conducted through the combined organic substrates in the first instance. Water vapour, which is at a temperature below the saturated temperature, condenses on the inner wall of the cylindrical reactor and forms a film of water through which heat travel. Heat then flows across the wall of the reactor by conduction, after which it is dissipated to the surroundings by free-convection convective heat transfer. Figure 1 presents the conceptual model of the combined boundary layer/fluid film theory and the conductive heat flow processes occurring in a self-heating compost matrix.

The TRP-model for $U$-value evaluation is described in general terms by:

$$
U=\frac{C_{f^{\prime} o p t}}{\frac{X}{K}+\frac{A_{c o} \ln \left(r_{o} / r_{i}\right)}{2 \pi K_{s} L}+\frac{A_{c o}}{A_{c i}} \frac{1}{h_{w s i}}+\frac{1}{h_{o}}}
$$

where $U=$ overall heat-transfer coefficient $\left(\mathrm{W} / \mathrm{m}^{2} \cdot \mathrm{K}\right) ; C_{f, o p t}=$ optimum correction factor (positive numerical constant); $A_{c o}=$ outside surface area of cylinder $\left(\mathrm{m}^{2}\right) ; A_{c i}=$ inside surface area of cylinder $\left(\mathrm{m}^{2}\right) ; h_{w s i}=$ film heat transfer coefficient in water condensate film on inner surface area of cylinder $\left(\mathrm{W} / \mathrm{m}^{2} \cdot \mathrm{K}\right)$; $h_{o}=$ convective heat transfer coefficient between outside surface of reactor and room $\left(\mathrm{W} / \mathrm{m}^{2} \cdot \mathrm{K}\right) ; r_{o}=$ inner radius of bioreactor from centre to inner surface $(\mathrm{m}) ; r_{i}=$ inner radius of compost material which is at constant temperature $(\mathrm{m}) ; L=$ reactor length $(\mathrm{m}) ; X=$ thickness of reactor wall with insulation (m); $K_{s}=$ thermal conductivity of compost bed material $(\mathrm{W} / \mathrm{m} \cdot \mathrm{K}) ; K=$ thermal conductivity of wall material (typically PVC) $(\mathrm{W} / \mathrm{m} \cdot \mathrm{K})$.

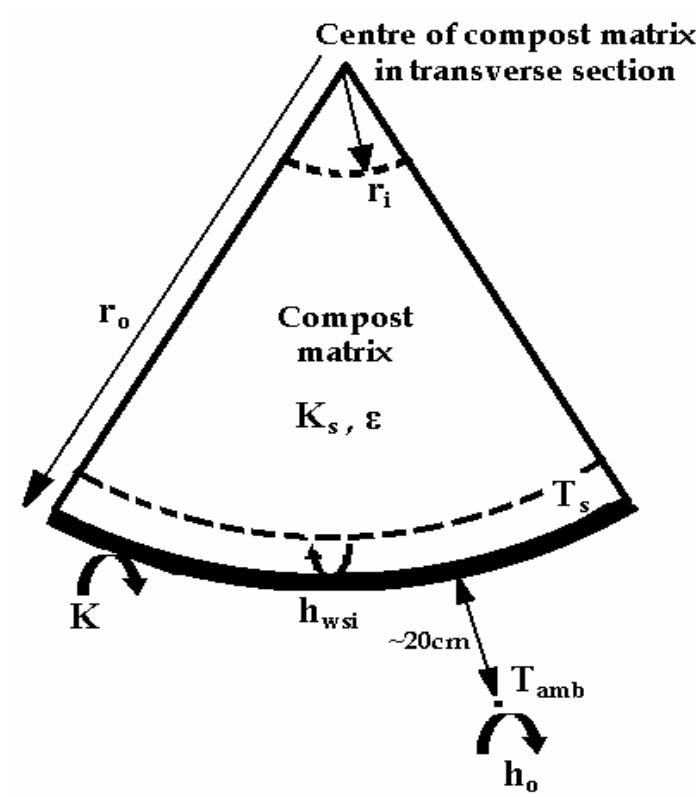

Figure 1. Conceptual schematic of TRP-model for a section of compost in reactor.

$A_{c o}$ and $A_{c i}$ are further expressed in terms of the internal diameter $D(\mathrm{~m})$ and reactor wall thickness $X(\mathrm{~m})$ as:

$A_{c o}=\pi \frac{(D+2 X)^{2}}{4}$

$A_{c i}=\pi \frac{D^{2}}{4}$

The thermal conductivity of the compost bed material $K_{s}$ is approximated by:

$K_{s}=0.0264 \varepsilon+(1-\varepsilon) k_{c}$

where $\varepsilon$ is the average free airspace (FAS) (decimal fraction) of the compost matrix and $k_{c}$ is the average thermal conductivity of the compost substrates only $(\mathrm{W} / \mathrm{m} \cdot \mathrm{K})$.

The average film heat transfer coefficient $\left(h_{w s i}\right)$ due to filmwise condensation of water vapour on the inner surface of the reactor is expressed as:

$h_{\text {usi }}=0.725\left[\frac{k^{3} g \rho_{l}\left(\rho_{l}-\rho_{v}\right)\left[h_{f}+\frac{3}{8} c_{p L}\left(T_{\text {sat }}-T_{w}\right)\right]}{\mu_{l} D\left(T_{\text {sat }}-T_{w}\right)}\right]^{1 / 4}$

where $\rho_{l}$ and $\rho_{v}$ are the densities of liquid and vapour, respecttively $\left(\mathrm{kg} / \mathrm{m}^{3}\right), h_{f}$ is the specific enthalpy of saturated liquid $(\mathrm{J} / \mathrm{kg}), \mu_{l}$ is the dynamic viscosity of water (Pa.s), $T_{\text {sat }}$ corresponds to the saturation temperature $(\mathrm{K}), T_{w}$ is the average temperature of the water condensate at the boundary of con- 
densate and reactor wall $(\mathrm{K}), c_{p l}$ is the specific heat capacity of the water condensate $(\mathrm{J} / \mathrm{kg} \cdot \mathrm{K}), g$ is equal to $9.81 \mathrm{~ms}^{-2}$, and $k$ is the thermal conductivity of water $(\mathrm{W} / \mathrm{m} \cdot \mathrm{K})$.

$T_{w}$ is deduced from Equation (6):

$T_{w}=T_{\text {sat }}-\frac{3}{4}\left(T_{\text {sat }}-T_{s}\right)$

where $T_{s}$ is the inner average surface temperature of the reactor wall (K).

The film transfer coefficient due to convective heat transfer between the outer surface of the reactor wall and the immediate air layer was determined using the Churchill and Chu (1975) correlation expressed as:

$h_{o}=\frac{k_{a}}{L}\left\{0.825+\frac{0.387 R a_{L}^{1 / 6}}{\left[1+(0.492 / P r)^{9 / 16}\right]^{8 / 27}}\right\}^{2}$

where $k_{a}$ is thermal conductivity of air $(\mathrm{W} / \mathrm{m} \cdot \mathrm{K}) ; P_{r}$ is Prandtl number (dimensionless); $R_{a}$ is Rayleigh number (dimensionless).

The Prandtl and Rayleigh numbers (Equations 8 and 9, respectively) are expressed as:

$$
\begin{aligned}
& \operatorname{Pr}=\frac{\mu_{a} c_{p a}}{k_{a}} \\
& R a=\operatorname{Pr} \cdot G r=\operatorname{Pr} \cdot \frac{g \beta\left(T_{s}-T_{a m b}\right) L^{3}}{v_{a}{ }^{2}}
\end{aligned}
$$

where $G_{r}$ is Grashof number; $\mu_{a}$ is dynamic viscosity of air $(\mathrm{Pa} \cdot \mathrm{s}) ; C_{p a}$ is specific heat capacity of air $(\mathrm{J} / \mathrm{kg} \cdot \mathrm{K}) ; \beta$ is coefficient of thermal expansion $(1 / \mathrm{K}) ; v_{a}$ is kinematic viscosity of air $\left(\mathrm{m}^{2} / \mathrm{s}\right) ; T_{a m b}$ is average ambient air temperature $(\mathrm{K})$.

\section{Multi-Parameter Sensitivity Analysis}

From the prior model description, it is clear that the TRPmodel contains a large number of parameters (21 basic nonredundant parameters) that influence the value of the $U$-value. In practice, each of these parameters will vary over some range that can be subdivided to obtain a set of values for the parameter. To assess all possible combinations of the parameters, the total number of model evaluations would equal the product of all the values. For each model evaluation, several responses are possible and depending upon the model application, one or more of these responses may be of interest. Hence, the entire data set produced from such an exercise will be multiplied by the number of responses that are employed (Parker, 1997). The computational requirements required to determine regions of model sensitivity become substantial if the number of parameters is greater than 3 and the number of values of each parameter is greater than 10 (Parker, 1997).
An approach that can be employed to assess model response is to use a combined multi-parameter sensitivity analysis and frequency array or graphical approach. This technique has been employed elsewhere to assess emissions from sewer systems (Hornberger and Spear, 1980; Chang and Delleur, 1992; Corsi and Birkett, 1995; Choi et al., 1998; Choi, 1998) for determining the relative importance of factors influencing the natural attenuation of mining contaminants (Choi et al., 1999) and in quantifying the importance of the parameters in models developed to describe the fate of volatile organic compounds in trickling filters (Parker, 1997). The MPSA approach allows an assessment of the importance of each input parameter at a variety of settings of the other input parameters (Rabinowitz and Steinberg, 1991; Parker, 1997; Choi et al., 1999) and thus provides a more realistic picture than the standard analyses (Deshusses, 1994; Stombaugh and Nokes, 1996; Liang et al., 2004; Xi et al., 2005; Baquerizo et al., 2005). Standard analyses assess each input parameter only at the default values of the other parameters (Rabinowitz and Steinberg, 1991; Hamby, 1994) while in MPSA; a pairwise evaluation of the parameters is performed to allow for the development of three-dimensional response curves. For the evaluation of a given pair of parameters (primary parameters) (Parker, 1997), all of the non-selected parameters are designnated secondary parameters. At each combination of the primary parameters, the model is evaluated for all of the combinations of the secondary parameters. To reduce the number of the responses obtained for each combination of the primary parameters to a single value, a removal criterion is defined (Parker, 1997). This criterion is set to a level at which the response is considered significant. The matrix of responses that is subsequently obtained can be plotted as a three-dimensional surface that allows for visual assessment of the model sensitivity, and subsequently identify which input parameters influence the model's response the most. The frequency array plot generated provides an indication of the potential for obtaining a significant response for a given combination of the primary parameters. An elevated value in the plot would indicate a combination that will result in a potential "hot-spot" (Parker, 1997). The frequency plot can also be employed to identify areas of rapid change in the plot surface, as these are indicative of regions of model sensitivity, and decide on the optimum range(s) of parameters that satisfy the criterion. It must be noted that the results of this technique may not necessarily indicate the results that might be obtained from the model for any given composting matrix, but will effectively indicate the fraction of the population of values that will exceed a given criterion.

\subsection{Equation Formulation and Parameter Identification}

Given the large number of parameters in the TRP-model, it was not possible to evaluate all of the parameters in this study. Parameters were selected for evaluation from two broad categories representing reactor design conditions and thermophysical properties of the compost matrix. The reactor design conditions included the dimensions of the reactor in terms of 
the length $(L)$, the internal diameter $(D)$, the thickness of the wall with insulation $(X)$ and the thermal conductivity of the reactor wall material $(K)$. The thermophysical compost matrix properties included the average free airspace $(\varepsilon)$, the thermal conductivity of the compost matrix $\left(K_{c}\right)$, and the inner surface temperature $\left(T_{s}\right)$ of reactor. The remaining parameters that involved in the TRP-model showed relatively small variations ( 0.044 to $5.3 \%$ about their respective mean values over the temperature range of $26.0^{\circ} \mathrm{C}$ to $60.1^{\circ} \mathrm{C}$ recorded during the composting process.

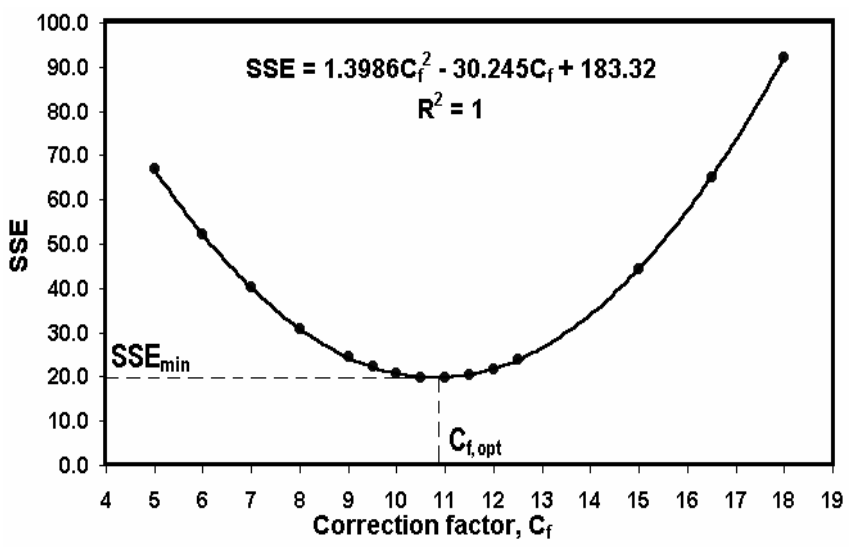

Figure 2. Variation of sum of squares of errors (SSE) for mean errors between $U$-values from TRP-model and corresponding values from energy balance.

The optimum correction factor $\mathrm{C}_{f, \text { opt }}$ is a numerical constant incorporated in Equation 1 to reconcile the $U$-values predicted from the TRP model as close as possible to those predicted by the energy balance. This correction factor was required since the TRP model predicted the $U$-values well only qualitatively but produced a systematic difference when compared to the results from the energy balance. Also, including a correction factor would bring both sets of model results on a similar basis for comparison, and thus be more amenable to further statistical analysis. The choice of an optimum correction factor $\left(\mathrm{C}_{f \text {,opt }}\right)$ was based on a particular value that resulted in the least numerical differences between the two sets of values. The mean sum of squares of errors (SSE) was calculated for a series of $\mathrm{C}_{f}$ and the result used to assess this numerical difference (Figure 2). The minimum SSE ( $\mathrm{SSE}_{\min }$ ) was 19.817 and corresponded to $\mathrm{C}_{f}=10.812$. The $X / K$ term (Equation 1 ), which is the resistance to heat transfer by conduction across the bioreactor wall material, has been modeled in terms of rectangular coordinates in Equation 1. However, the thickness of the insulating material over the outside wall would vary when redesigning the bioreactor, and the ratio of the internal diameter to the thickness of insulation $(D / X)$ might consequently become significant. In this respect, this term was expressed in terms of the corresponding cylindrical coordinates to minimize estimation errors. Hence, based on the mean values for the non-varying physical parameters, taking $\mathrm{C}_{f, o p t}$ to be 10.812 and including the abovementioned modification in geometry, Equation 1 was rewritten to Equation 10:

$$
U=\frac{10.812}{\left\{\begin{array}{l}
\frac{\ln \left(1+\frac{2 X}{D}\right)}{2 \pi K L}+\frac{0.201(D+2 X)^{2}}{L\left[0.0264 \varepsilon+(1-\varepsilon) K_{c}\right]} \\
+9.67 * 10^{-4}\left(1+\frac{2 X}{D}\right)^{2}\left[\frac{D\left(372.6-T_{s}\right)}{488.9-T_{s}}\right]^{1 / 4} \\
+\frac{0.663 L}{\left[0.109+\left(T_{s}-298\right)^{1 / 6} \sqrt{L}\right]^{2}}
\end{array}\right\}}
$$

\subsection{1. $L$ and $D$}

In this study, the length of the reactor was varied between $0.40 \mathrm{~m}$ and $2.50 \mathrm{~m}$ and the diameter was varied from $0.20 \mathrm{~m}$ to $1.20 \mathrm{~m}$. The proposed ranges for the length and diameter included values that have been chosen when designing and experimenting on similar compost bioreactors (Liao et al., 1994; Nakasaki et al., 1997; Darrell et al., 1998; Day et al., 1998; Freeman and Cawthon, 1999; Lehmann et al., 1999; Vining, 2002; Ekinci et al., 2004a,b; Hess et al., 2004; Hong and Park, 2004; Petiot and de Guardia, 2004; Mason and Milke, 2005; Yu et al., 2005).

\subsection{2. $K$}

The thermal conductivity range for the reactor wall material and insulation tested in the analysis was $0.029 \mathrm{~W} / \mathrm{m} \cdot \mathrm{K}$ to $0.50 \mathrm{~W} / \mathrm{m} \cdot \mathrm{K}$. This range encompassed the thermal conductivities of a variety of plastics and insulation materials (expanded polystyrene, polystyrene, high density polythene, cotton wool, corkboard, hardboard, glass wool, fiberglass, foams (Styrofoam), polyurethane (Hogan et al., 1989; Bari et al., 2000; Adani et al., 2001; Ekinci et al., 2004b; Petiot and de Guardia, 2004; Mason and Milke, 2005; Ghaly et al., 2006)* of which the reactor could be lagged.

\subsection{3. $X$}

The thickness of the wall of the bioreactor varied from $0.004 \mathrm{~m}$ (actual thickness of compost reactor wall) to $0.060 \mathrm{~m}$ (Hong and Park, 2004; Mason and Milke, 2005; Ghaly et al., 2006). The increase in thickness would constitute an additional insulation for the compost matrix, and hence provide more resistance to heat loss. An important implication would be that more insulation would help maintain the compost matrix at the high thermophilic temperatures for longer periods of time during the initial stages of biodegradation and allow for improved organic matter decomposition rates.

\subsection{4. $\varepsilon$}

The free airspace range of 0.10 to 0.82 tested in this study was selected based on the results of numerous previous

\footnotetext{
*Source for thermal conductivity data: http://www.engineeringtoolb ox.com/thermal-conductivity-d_429.html
} 
studies conducted to study free airspace variation in different composts (Haug, 1993; Annan and White, 1998; Baker et al., 1998; van Ginkel et al., 1999; McCartney and Chen, 2000; Richard et al., 2002; Agnew et al., 2003; Agnew and Leonard, 2003; Veeken et al., 2003; Richard et al., 2004; Mohee and Mudhoo, 2005).

\subsection{5. $K_{c}$}

Rahman (1984) investigated the thermal properties of a variety of composts and found linear relationships between moisture content and thermal conductivity of the compost bed. The values ranged from $0.218 \mathrm{~W} / \mathrm{m} \cdot \mathrm{K}$ to $0.805 \mathrm{~W} / \mathrm{m} \cdot \mathrm{K}$. These values are of the same order as those reported by Seki (1989) who gave values of $0.698 \mathrm{~W} / \mathrm{m} \cdot \mathrm{K}$ for compost made from chicken and cattle manure with sawdust and rice hulls. Iwabuchi and Kamide (1993) described a thermal probe for determining the thermal conductivity for compost made from dairy manure and sawdust, and values of conductivity obtained were $0.0508 \mathrm{~W} / \mathrm{m} \cdot \mathrm{K}$ and $0.0956 \mathrm{~W} / \mathrm{m} \cdot \mathrm{K}$ for materials at moisture contents of 0 and $57.1 \%$ (wet basis) respectively. The variability in the thermal conductivity of composts is therefore relatively large over the range of moisture contents observed in composting experiments. Based on the results obtained for thermal conductivity variation in composting experiments, a range of 0.050 to $0.900 \mathrm{~W} / \mathrm{m} \cdot \mathrm{K}$ of the compost materials was suggested for the sensitivity analysis.

\subsection{6. $T_{s}$}

$T_{s}$ was tested in the range $25.0^{\circ} \mathrm{C}$ to $75.0^{\circ} \mathrm{C}$ (298 to 348 $\mathrm{K})$ since this range corresponded to temperatures that were recorded in various composting experiments (Marugg et al., 1993; Kaiser, 1996; Das and Keener, 1997; Korner et al., 1997; Nakasaki et al., 1997; Day et al., 1998; Fauci et al., 1999; Raviv et al., 1999; Robinzon et al., 1999; Vuorinen and Saharinen, 1999; Lemus and Lau, 2002; Venelampi et al., 2003; Hess et al., 2004; Ekinci et al., 2004b; Hong and Park, 2004; Lyberg and Hogland, 2004; Mohee and Mudhoo, 2005; Ghaly et al., 2006).

\subsection{Parameter Discretization}

Seven parameters were identified for the sensitivity analysis (Equation 10). The discretization of the range of each parameter into individual values must span the endpoints previously described and also reflect the relative distribution of values that may be encountered in practice. The fact that the average surface temperature is actually a process output parameter, it becomes necessary to use a distribution in the analysis that ensures $T_{s}$ depicts the different stages of the composting process. In this respect, and in order to eliminate any bias during the model assessment, the logarithmic approach developed by Parker (1997) was used to determine the discretized values. In such a method, a multiplier was determined as:

$\phi=\left(\frac{P_{f}}{P_{0}}\right)^{\frac{1}{n}}$ where $P_{f}$ and $P_{o}$ are high and low endpoints of the parameter range, respectively; $n$ is number of intervals in range; $\phi$ is a multiplier.

The values of the parameters were then calculated from:

$P_{i}=\phi^{i} P_{0}$

where $i=0, n$. This approach, in principle, ensures that when a parameter range spans several orders of magnitude, each order of magnitude is represented in the model evaluation process (Parker, 1997). This technique was employed to calculate discretized parameter values. In this study, six intervals $(n=6)$ were employed for each parameter, resulting in a total of seven values for each parameter being assessed. The actual values evaluated for each parameter are presented in Table 1.

Table 1. Discretized Parameter Values Tested in Multi-Parameter Sensitivity Analysis

\begin{tabular}{ccccccc}
\hline \multicolumn{3}{c}{ Design properties } & \multicolumn{3}{c}{ Thermophysical properties } & $\begin{array}{c}\text { Substrate } \\
\text { property }\end{array}$ \\
\cline { 1 - 5 } $\begin{array}{c}\mathrm{L} \\
(\mathrm{m})\end{array}$ & $\begin{array}{c}\mathrm{X} \\
(\mathrm{m})\end{array}$ & $\begin{array}{c}\mathrm{D} \\
(\mathrm{m})\end{array}$ & $\begin{array}{c}\mathrm{K} \\
(\mathrm{W} / \mathrm{m} \cdot \mathrm{K})\end{array}$ & $\begin{array}{c}K_{C} \\
(\mathrm{~W} / \mathrm{m} \cdot \mathrm{K})\end{array}$ & $\begin{array}{c}T_{s} \\
(\mathrm{~K})\end{array}$ & $\varepsilon$ \\
\hline 0.40 & 0.004 & 0.20 & 0.029 & 0.050 & 298.0 & 0.10 \\
0.54 & 0.006 & 0.27 & 0.047 & 0.081 & 305.8 & 0.14 \\
0.74 & 0.010 & 0.36 & 0.075 & 0.131 & 313.8 & 0.20 \\
1.00 & 0.015 & 0.49 & 0.120 & 0.212 & 322.0 & 0.27 \\
1.36 & 0.024 & 0.66 & 0.194 & 0.343 & 330.5 & 0.41 \\
1.84 & 0.038 & 0.89 & 0.311 & 0.556 & 339.1 & 0.58 \\
2.50 & 0.060 & 1.20 & 0.500 & 0.900 & 348.0 & 0.82 \\
\hline
\end{tabular}

\subsection{Frequency Array Plots for Primary Parameter Pairs}

A total of seven design, thermophysical and matrix parameters have been identified for evaluation and, if all pair-wise combinations were considered, 21 plots would be required. To minimize the number of plots, the parameters have therefore been sorted into the categories of design or geometrical conditions, substrate properties, and thermophysical properties. 15 primary parameter pair combinations were tested within categories and between categories. Based on the results and on the practical significance of a particular primary parameter pair in the composting process, only seven selected combinations had been retained and are summarized in Table 2. The comparisons within the categories were identified on the basis of potential competition between the specific category parameters. For example, variations in $L$ and $D$ might compete to determine the geometrical design of the reactor, and thence control the volume of substrates that can be composted. The comparisons between categories were selected on basis of likely interaction between parameters. For example, variations in $\varepsilon$ and $K_{c}$ are likely to interact to influence the mode and rate of air and heat flow within the compost matrix. For a chosen pair out of the seven selected primary parameter pairs, a total 
of 49 combinations are possible among the values. Selecting a pair of primary parameters leaves out five secondary parameters (Table 1). The corresponding total number of combinations of secondary parameters that can be tested for a single combination of primary parameters is $7^{5}(16,807)$. Hence, the total number of combinations to be simulated by the model (Equation 10) amounts to 823,543. Realizing the substantial computational requirements for performing the latter calculations, a program was written in MATLAB ${ }^{\circledR} 7.0$ to evaluate the $U$-values for each and every combination of the seven model parameters. All the possible combinations were deduced using a Trellis search algorithm (Proakis, 2000) embedded in the program. For each combination of a primary parameter pair, the $U$-values obtained were screened for the criterion of exceedance, and all values exceeding this criterion $(E)$ were enumerated. The total obtained was divided by 16,807 and the resultant value $(f)$ plotted against the corresponding primary parameters on a three-dimensional plot using the SigmaPlot9.0 software (2004 SYSTAT Software, Inc.)

Table 2. Primary Parameter Pairs Tested in MPSA and Frequency Array Analysis

\begin{tabular}{llll}
\hline$L$ vs. $X$ & $D$ vs. $\varepsilon$ & $X$ vs. $K$ & $X$ vs. $D$ \\
\cline { 1 - 2 }$L$ vs. $D$ & $\varepsilon$ vs. $K_{c}$ & $D$ vs. $K_{c}$ & \\
\hline
\end{tabular}

\subsection{Single-Parameter Frequency Analysis}

The frequency array plots would provide a clear indication of the range of values for every parameter in Equation 10 over which the model is the most sensitive. While these data were helpful for future redesign of the reactor, the sensitivity analysis proposed by Choi et al. (1999) would still provide an additional set of results that would identify which input parameters influence the model response the most. Realizing the relevance of an additional statistical test, the model in this study was further analyzed based on the method of Choi et al. (1999) by using a second program written in MATLAB ${ }^{\circledR} 7.0$. While the approach of Choi et al. (1999) made an extensive use of Monte-Carlo simulations, the method used in this study consisted in evaluating the parametric sensitivity statistically. For each parameter, the distributions of the parameter values associated with the acceptable and unacceptable results were compared with the exceedance criterion $(E)$. Model outputs that were less than $E$ were classified acceptable while those greater than $E$ unacceptable. For every value of a parameter, $7^{6}(117,649)$ responses were obtained. The frequency distribution for acceptable and unacceptable results for a particular parameter was obtained by plotting the frequency of acceptable and unacceptable results for every of the discretized parameter values listed in Table 1 . The frequency of acceptable results $\left(f_{a}\right)$ was calculated by dividing the total number of model responses giving acceptable results by 117,649 , and the frequency for unacceptable results was $1-f_{a}$. If the two distributions were not statistically different, the parameter was classified as insensitive; otherwise, the parameter was classified as sensitive. The results of the frequency analysis of the
TRP-model were interpreted in comparison with the concepttual frequency distributions of typical sensitive and insensitive model parameters reported in Choi et al. (1999).

\subsection{Criteria for Exceedance}

A key feature of the frequency array analysis method is the identification of exceedance criteria (Parker, 1997). In this study, the rate of heat loss from the composting matrix is characterized by the $U$-values developed at the different process temperatures. In most composting experiments, the objective is to maintain thermophilic temperatures $\left(45^{\circ} \mathrm{C}\right.$ to $60^{\circ} \mathrm{C}$ ) (Rothbaum, 1960; MacGregor et al., 1981; Ekinci et al., 2004a; Hong and Park, 2004) for 3 to 4 days, allow an optimum biodegradation to take place through optimum microbial activity (Stombaugh and Nokes, 1996; Brinkmann et al., 1997; Taiwo and Oso, 2004) and thus ensure maximum stabilization and sanitization of the organic matter (Haug, 1993). High $U$ values during the active thermophilic stage (metabolic heat output is normally most during this stage) will cause higher rates of heat loss (Foust et al., 1980) and reduce the duration of the thermophilic temperatures in the compost matrix. In this respect, relatively low $U$-values would be preferred in composting. As such, the criteria for exceedance of different responses (model outputs) for different compost matrices will have different values. Maximum $U$-values from the energy balance approach ranged from $4.52 \mathrm{~W} / \mathrm{m}^{2} \cdot \mathrm{K}$ to $8.57 \mathrm{~W} / \mathrm{m}^{2} \cdot \mathrm{K}$ from day 2 to day 5 of the composting process for compost matrix temperatures varying between $55.1^{\circ} \mathrm{C}$ and $62.1^{\circ} \mathrm{C}$ during this period. On the other hand, the $U$-values from the corrected TRP-model (with correction being made only for $\boldsymbol{C}_{\boldsymbol{f}}$ in Equation 1) vary from $2.76 \mathrm{~W} / \mathrm{m}^{2} \cdot \mathrm{K}$ to $4.18 \mathrm{~W} / \mathrm{m}^{2} \cdot \mathrm{K}$ for the same temperature range. Thus, the choice of $\boldsymbol{E}$ becomes particularly arbitrary. Hence, for the selected comparisons of primary parameters, the exceedance criterion was varied to assess its impact on the conclusions drawn from the frequency array plots. For a minimum $U$-value of $0.14 \mathrm{~W} / \mathrm{m}^{2} \cdot \mathrm{K}$ and a maximum of $58.01 \mathrm{~W} / \mathrm{m}^{2} \cdot \mathrm{K}$ obtained after evaluation of all combinations, $14 U$-values were tested for the seven primary parameter pairs. These values were calculated by dividing the range 0.14 to $58.01 \mathrm{~W} / \mathrm{m}^{2} \cdot \mathrm{K}$ into 13 equal intervals. Based on the frequency array plots that were generated for these $U$ values, the exceedance criteria retained for further analysis were $4.5,13.5$ and $23.0 \mathrm{~W} / \mathrm{m}^{2} \cdot \mathrm{K}$.

\section{Results and Discussion}

The results of the multi-parameter sensitivity analyses can be assessed to better understand how interactions between substrates-specific properties and reactor design properties have influenced the rates of heat loss from the composting system. The frequency array (surface) plots for the comparison of internal diameter with the free airspace, thermal conductivity of insulation material with reactor wall and insulation thickness, and internal diameter with reactor wall and insulation thickness are discussed below for the three criteria of exceedance that were retained. The frequency distributions for single-parameter sensitivity analysis for $E=4.5 \mathrm{~W} / \mathrm{m}^{2} \cdot \mathrm{K}$ 
are grouped in Figure 3. The first set of results from the parameter pair approach gives an indication of the interaction of two physical properties and their optimum ranges of values satisfying the process criteria for minimal heat loss. Figure 3 identifies which parameters have had the most influence on the model responses.

\subsection{Analysis of Frequency Array Plots}

\subsection{1. $L$ vs. $X$}

Based on the frequency array plot obtained for the comparison of reactor length and the combined reactor wall and insulation thickness, it was observed that the model remained insensitive for values of $L$ greater than $1.5 \mathrm{~m}$. The model response became favourable towards smaller heat transfer coefficients for $L<1.5 \mathrm{~m}$ and $X>0.03 \mathrm{~m}$ since the surface showed sharp slopes in these parameter ranges, and frequency values shifted from 0.70 towards smaller values of 0.3 to 0.5 . The optimum ranges of values that showed minimum exceedance with respect to $E=4.5 \mathrm{~W} / \mathrm{m}^{2} \cdot \mathrm{K}$ corresponded to $1.0 \mathrm{~m}<L<$ $1.5 \mathrm{~m}$ and $X>0.04 \mathrm{~m}$. Frequency surface plots for $E=13.5$ $\mathrm{W} / \mathrm{m}^{2} \cdot \mathrm{K}$ and $E=23.0 \mathrm{~W} / \mathrm{m}^{2} \cdot \mathrm{K}$ showed that a smaller number of model responses exceeded the corresponding exceedance criterion for values of $L$ less than $1.5 \mathrm{~m}$ and $X$ greater than $0.03 \mathrm{~m}$. The gradual flattening of the surfaces for the successsive criterion for exceedance towards frequency values nearing 0 supported the fact that for relatively small-length reactors, an increase in the thickness of insulation favoured model responses not exceeding the set criterion.

\subsection{2. $D$ vs. $L$}

For $E=4.5 \mathrm{~W} / \mathrm{m}^{2} \cdot \mathrm{K}$, the model responses remained unfavourable for values of $L$ greater than $1.5 \mathrm{~m}$ and for $D$ less than $0.55 \mathrm{~m}$. The surface of the plot remained nearly flat in these ranges at high frequency values of 0.7 to 0.8 . The model showed significant sensitivity for values of $L$ and $D$ slightly less than $1.5 \mathrm{~m}$ and greater than $0.6 \mathrm{~m}$, respectively since the frequency of combinations giving $U$-values greater than 4.5 $\mathrm{W} / \mathrm{m}^{2} \cdot \mathrm{K}$ decreased for frequencies ranging between 0.2 and 0.35 . A similar gradual flattening behaviour was observed for the other two criteria of exceedance. Values of $L$ from $1.0 \mathrm{~m}$ to $1.5 \mathrm{~m}$ and larger internal diameters $(0.6 \mathrm{~m}<D<1.2 \mathrm{~m})$ gave reactor geometries that would be expected to minimize heat loss from the composting matrix.

\subsection{3. $K_{c}$ vs. $D$}

While the interaction between the thermal conductivity of the compost materials and the internal diameter of the reactor may not be clearly understood, the results showed two main observations. First, the model response with respect to the three criteria of exceedance for the thermal conductivity remained poor from a process performance point of view. This was because either criterion was not exceeded for values in the lowermost range of values of $K_{c}(<0.1 \mathrm{~W} / \mathrm{m} \cdot \mathrm{K})$. However, model sensitivity became prominent only as a result of the larger values of internal diameter. This observation was supported by the abrupt decrease in exceedance frequency from
0.8 to much lower values of 0.2 for $K_{c}<0.1 \mathrm{~W} / \mathrm{m} \cdot \mathrm{K}$ for $E=$ $4.5 \mathrm{~W} / \mathrm{m}^{2} \cdot \mathrm{K}$. The slight flattening that was observed in the two remaining array plots $\left(E=13.5\right.$ and $\left.E=23.0 \mathrm{~W} / \mathrm{m}^{2} \cdot \mathrm{K}\right)$ occured mainly due to the influence of the large values of $D$ (0.8 to $1.2 \mathrm{~m})$

\subsection{4. $\varepsilon$ vs. $D$}

The results for the pairing of the free air space of the composite matrix with the internal diameter of the reactor showed that while the magnitude of the diameter influenced the volume of empty space (air-filled porosity) with the matrix by producing a more or less dispersed distribution of compost particles, their interactions appeared to be most observable and influential on the rate of heat loss at higher values. The array plot for $E=23.0 \mathrm{~W} / \mathrm{m}^{2} \cdot \mathrm{K}$ indicated a region of low and a region of high sensitivity. For values of $D$ and free airspace between $0.7 \mathrm{~m}$ and $0.2 \mathrm{~m}$ and less than $50.0 \%$, respectively, the frequency values for exceedance remained relatively higher at 0.10 to 0.25 . For parameter values falling in the upper bounds of the respective parameter ranges tested, the frequency of parameter combinations producing high $U$ values, and thus higher rates of heat loss, decreased to near zero. Hence, large internal diameters ranging from 0.8 to 1.2 $\mathrm{m}$, and average free airspace contents greater than $55.0 \%$ favour lower rates of heat removal.

\subsection{5. $\varepsilon$ vs. $K_{c}$}

A general observation from the frequency array plots obtained from the comparison of free airspace of the matrix and thermal conductivity of the compost materials indicated that the surfaces tended to flatten down to frequencies nearing zero for larger values of each parameter. While all three plots indicated regions of low and high sensitivity, the array plot for $E=4.5 \mathrm{~W} / \mathrm{m}^{2} \cdot \mathrm{K}$ showed the most significant shifts from high frequency to low frequency. For thermal conductivity decreasing from $0.9 \mathrm{~W} / \mathrm{m} \cdot \mathrm{K}$ to $0.5 \mathrm{~W} / \mathrm{m} \cdot \mathrm{K}$ and free airspace increaseing from 0.1 to 0.5 , the number of combinations exceeding $E$ $=4.5 \mathrm{~W} / \mathrm{m}^{2} \cdot \mathrm{K}$ remained high since the observed frequencies fluctuated between 0.7 and 0.85 . A notable decrease in the exceedance frequencies ( 0.2 to 0.4$)$ was then observed from the sharp fall in surface contour for porosities beyond $50.0 \%$ and thermal conductivities below $0.4 \mathrm{~W} / \mathrm{m} \cdot \mathrm{K}$. A compost mixture with materials having a relatively low thermal conductivity cannot provide a direct indication on the amount of heat that can be released within the matrix following microbial degradation, but surely supports the fact the heat thus generated will be less easily conducted from the core of the matrix to the cooler regions of the reactor. Coupled to that, the high free airspaces would imply having a relatively well-aerated matrix with more air acting as an insulator to heat loss by combined conduction and convection.

\subsection{6. $X$ vs. $K$}

For $X$ ranging from $0.004 \mathrm{~m}$ to $0.06 \mathrm{~m}$ and with values for $K$ between $0.20 \mathrm{~W} / \mathrm{m} \cdot \mathrm{K}$ and $0.5 \mathrm{~W} / \mathrm{m} \cdot \mathrm{K}\left(E=4.5 \mathrm{~W} / \mathrm{m}^{2} \cdot \mathrm{K}\right)$, the frequency of outputs exceeding the criterion was moderately high at 0.68 . However, for $0.04 \mathrm{~m}<X<0.06 \mathrm{~m}$ and $K$ 
lesser than $0.20 \mathrm{~W} / \mathrm{m} \cdot \mathrm{K}$, there was a drastic decrease in frequency of exceedances down to values less than 0.40 . This indicated that the use of insulation materials with low thermal conductivities for thicknesses of $4 \mathrm{~cm}$ to $6 \mathrm{~cm}$ tended to minimize the rate of heat loss from the composting matrix.

\subsection{7. $D$ vs. $X$}

The frequency array results obtained from the pair-wise comparison of internal diameter and thickness of wall and insulation showed that for $E=4.5$ and $E=13.5 \mathrm{~W} / \mathrm{m}^{2} \cdot \mathrm{K}$, the shift in sensitivity was only gradual as values for $D$ and $X$ were increased from the least value in their corresponding ranges to the maximum value. Although all three plots $(E=$ 4.5, $E=13.5$ and $E=23.0 \mathrm{~W} / \mathrm{m}^{2} \cdot \mathrm{K}$ ) indicated that larger values for both parameters tended to decrease the number of model outputs exceeding the criteria of exceedance, the last two plots (for $E=13.5$ and $E=23.0 \mathrm{~W} / \mathrm{m}^{2} \cdot \mathrm{K}$ ) showed marked peaks ("hot-spots") for $X<0.01$ and $D<0.2 \mathrm{~m}$. The remaining combinations of primary parameter pairs resulted in frequencies less than 0.1 . The results agree with the previous frequency array results in the sense that the upper bound parameter values for internal diameter and insulation thickness should be preferably chosen for reactor design. The above results showed that the model is sensitive to the parameters within specific ranges. The most favourable ranges of values for the set of parameters have been summarized in Table 3 .

Table 3. Range of Values for Design and Substrate Parameters of Compost Reactor Determined from the Combined Multiparameter Sensitivity Analysis and Frequency Array Analysis

\begin{tabular}{ll}
\hline Parameter & Range of values \\
\hline$D(\mathrm{~m})$ & $0.8-1.2$ \\
$X(\mathrm{~m})$ & $0.04-0.06$ \\
$\varepsilon$ & $0.5-0.6$ \\
$L(\mathrm{~m})$ & $1.0-1.5$ \\
$K_{c}(\mathrm{~W} / \mathrm{m} . \mathrm{K})$ & $0.1-0.2$ \\
$K(\mathrm{~W} / \mathrm{m} . \mathrm{K})$ & Less than 0.2 \\
\hline
\end{tabular}

\subsection{Single-Parameter Frequency Distributions}

In order to determine which individual parameters have had the most influence on the model response, a frequencybased sensitivity analysis was performed. The results are presented in Figure 3. Since the extent of separation between the two cases of acceptable and unacceptable results, in principle, represents the degree of sensitivity of each parameter (Choi et al., 1999); free airspace, combined thickness of wall and insulation and internal diameter of reactor have been identified as the most important input parameters to Equation 10.

While the impact of the variation in the thickness of insulation on the rate and amount of heat lost (Lemus and Lau, 2002; Lyberg and Hogland, 2004) to the surroundings by the composting system is clear in the sense that a thicker layer of insulation will limit the heat loss rates, the interaction of free airspace and internal reactor diameter in controlling heat removal from the matrix is more intricate. The porosity and internal diameter will interact to influence the structural parameters of the compost matrix (compaction, free airspace itself, and permeability (Veeken et al., 2003). Compaction of the matrix materials is normally dependent on the depth and mass of compost left in the reactor. As the microbial degradation proceeds, the compost bed becomes more compacted, the wet bulk density increases (Mohee and Mudhoo, 2005), resulting in a decrease in porosity and, subsequently, permeability (Veeken et al., 2003). As the permeability of the compost matrix decreases, the velocity of natural (passive) convection decreases (Beukema et al., 1983) and less heat is removed from the pile. As the degradation is slowed down at temperatures exceeding $55^{\circ} \mathrm{C}$ (Hassen et al., 2002; Narihiro and Hiraishi, 2005), this situation should be prevented (Veeken et al., 2003). Hence, the range of optimal permeabilities is relatively small and this implies that feedstock composition and structure, and matrix dimensions should be given high priority in the design of compost reactors.

\subsection{Analysis of the Impact of Exceedance Criteria}

The frequency array technique required the definition of an exceedance criterion against which model estimates were compared. In this study, values were selected to represent the responses that would be considered substantial and significant within the context of assessing the rate of heat loss from a self-heating composting matrix. It is apparent, however, that the selection of these criteria might have had some influence on the conclusions extracted from the plots. An analysis of all the frequency array plots for the seven primary parameter pairs for $E=4.5,13.5$ and $23.0 \mathrm{~W} / \mathrm{m}^{2} \cdot \mathrm{K}$ was therefore performed. The only substantial difference between the plots was the relative magnitude of the frequency values, with the lower values observed for the case that had a higher exceedance criterion. This was to be expected, as fewer combinations of the parameters would be expected to exceed the higher criterion. Similar conclusions were reached with respect to the sensitivity to parameter values from every frequency array plot. The results therefore suggested that the conclusions drawn with respect to the model's sensitivity to the model parameters appeared to be independent of the exceedance criterion over the range of parameter values considered in this study.

\section{Conclusions}

The combined multi-parameter sensitivity analysis and frequency array method (MPSA/FAM) was employed to perform a screening study that identified the most sensitive ranges of parameters for a model that predicted the overall heattransfer coefficients for the invessel self-heating composting of mixed organic substrates. The conclusions reached using such a technique were found to be reasonably consistent over a range of exceedance criteria that were of practical interest $\left(4.5 \mathrm{~W} / \mathrm{m}^{2} \cdot \mathrm{K}, 13.5 \mathrm{~W} / \mathrm{m}^{2} \cdot \mathrm{K}\right.$ and $\left.23.0 \mathrm{~W} / \mathrm{m}^{2} \cdot \mathrm{K}\right)$. The additional sensitivity analysis that was performed based on a single- 

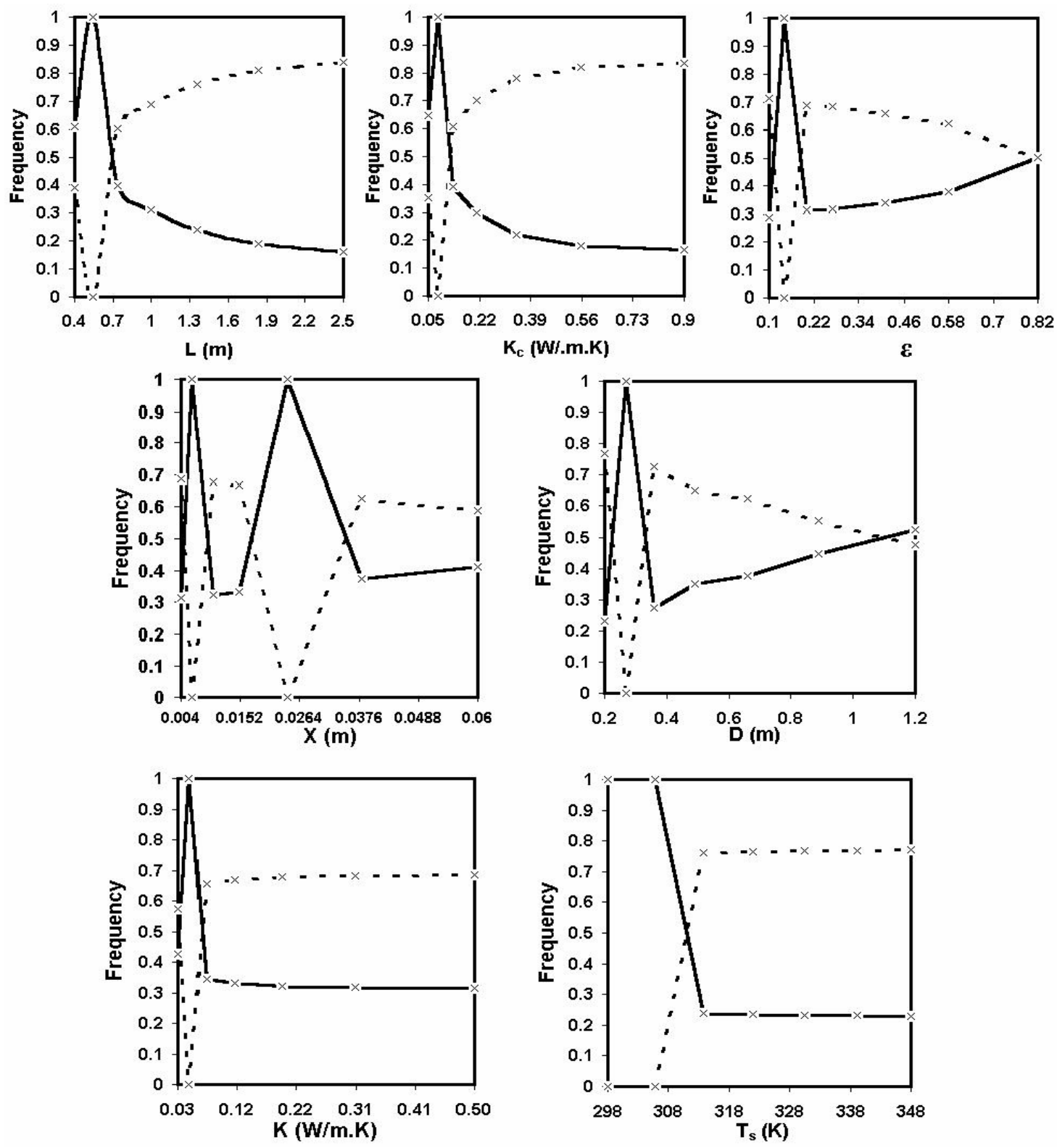

Figure 3. Results of frequency-based sensitivity analysis for model Equation 10. Solid and dashed lines indicate frequency distributions for acceptable $\left(f_{a}\right)$ and unacceptable $\left(1-f_{a}\right)$ cases, respectively.

parameter frequency-distribution-analysis technique confirmed that the free airspace of the compost matrix, the combined thickness of the reactor wall and insulation, and the internal diameter of the reactor were the most important input parameters affecting the model's response. The optimum ranges of values for the latter parameters as revealed from the MPSA/ FAM were 50 to $60 \%$ (FAS), $0.04 \mathrm{~m}$ to $0.06 \mathrm{~m}$ (thickness) and 0.8 to $1.2 \mathrm{~m}$ (internal diameter). The set of information obtained from the MPSA/FAM can be used to identify design and operating strategies that might be employed to minimize excessive heat losses during the initial thermophilic stages of the composting process. Furthermore, despite the fact that this technique generally requires extensive computational power, the end results provide a reliable guide for future data-collection efforts and to order research priorities.

\section{References}

Adani, F., Lozzi, P. and Genevini, P. (2001). Determination of biological stability of oxygen uptake on municipal soild wastes and derived products. Compost Sci. Util., 9(2), 163-178.

Agnew, J.M., Leonard, J.J., Feddes, J. and Feng, Y. (2003). A 
modified air pycnometer for compost air volume and density determination. Can. Biosyst. Eng., 45, 27-35.

Agnew, J.M. and Leonard, J.J. (2003). Literature review-the physical properties of compost. Compost Sci. Util., 11(3), 238.

Annan, J.S. and White, R.K. (1998). Evaluation of Techniques for measuring air-filled porosity in composts of Municipal Biosolids and Wood Chips, in K.C. Das and E.F. Graves, Proc. of the Conference of Composting in the South East.

Baker, S.M., Richard, T.L., Zhang, Z. and Monteiro da Rocha, S. (1998). Determining the free airspace inside compost mixtures using a gas pycnometer, in J.M. Agnew and J.J. Leonard (2003), Literature review-the physical properties of compost. Compost Sci. Util., 11(3), 238-264.

Baquerizo, G., Maestre, J.P., Sakuma, T., Deshusses, M.A., Gamisans, X., Gabriel, D. and Lafuente, J. (2005). A detailed model of a biofilter for ammonia removal: Model parameters analysis and model validation. Chem. Eng. J., 113, 205-214.

Bari, H.Q., Koenig, A. and Guihe, T. (2000). Kinetic Analysis of forced aeration composting-I, Reaction rates and temperature. Waste Manage. Res., 18, 303-312.

Beukema, K.J., Bruin, S. and Schenk, J. (1983). Three-dimensional natural convection in a confined porous medium with internal heat generation. Int. J. Heat Mass Transfer., 26, 451-458.

Brinkmann, U., Quast, T., Schneider, H., Helfer, A., Ehrig, H., Beutler, J., Gahrs, H.J. and Bockler, T. (1997). Phase Dependent Addition of Oxygen: A New Way to Improve the Composting Process, International Conference, Harrogate, UK, ORBIT 97, pp. 341-343.

Chang, F. and Delleur, J.W. (1992). Systematic parameter estimation of watershed acidification model. Hydrol. Process., 6, 29-44.

Choi, J., Harvey, J.W. and Conklin, M.H. (1999). Use of multiparameter sensitivity analysis to determine relative importance of factors influencing natural attenuation of mining contaminants, in Proc. of the U.S. Geological Survey Toxic Substances Hydrology Program-Technical Meeting, Charlestson, South Carolina, pp.185-92.

Choi, J. (1998). Transport Modeling of Metal Contaminants in a Stream-aquifer System, Ph.D. Dissertation, Department of Hydrology and Water Resources, University of Arizona, pp. 225.

Choi, J.Y., Hulseapple, S.M., Conklin, M.H. and Harvey, J.W. (1998). Modeling $\mathrm{CO}_{2}$ degassing and $\mathrm{pH}$ in a stream-aquifer system. $J$. Hydrol., 209, 297-310.

Churchill, S.W. and Chu, H.H.S. (1975). Correlating equations for laminar and turbulent free convection from a vertical plate. Int. J. Heat Mass Transfer., 18, 1323-1329

'Corsi, R.L. and Birkett, S. (1995). A multi-parameter analysis of volatile organic compound emissions from sewers. Wat. Env. Res., 67, 807.

Darrell, W.D., Chalmers, J.A. and Storey, J.A. (1998). Evaluation of in-vessel composting of University postconsumer food wastes. Compost Sci. Util., 6(2), 75-81.

Das, K. and Keener, H.M. (1997). Numerical model for the dynamic simulation of a large composting system. Trans. ASAE, 40(4), 1179-1189.

Day, M., Kryzymien, M., Shaw, K., Zaremba, L., Wilson, W.R., Botden, C. and Thomas, B. (1998). An investigation of the chemical and physical changes occurring during commercial composting. Compost Sci. Util., 6(2), 44-66.

Deshusses, M.A. (1994). Biodegradation of Mixtures of Ketone Vapours in Biofilters for the Treatment of Waste Air, Ph.D. Dissertation, Technical Sciences, Swiss Federal Institute of Technology, Zurich.

Ekinci, K., Keener, H.M., Michel, F.C.Jr. and Elwell, D.L. (2004a). Modeling composting rate as a function of temperature and initial moisture content. Compost Sci. Util., 12(4), 356-364.

Ekinci, K., Keener, H.M., Michel, F.C.Jr. and Elwell, D.L. (2004b).
Effects of aeration strategies on the composting process: Part I, experimental studies. Trans. ASAE, 47(5), 1697-1708.

Fauci, M.F., Bezdicek, D.F., Caldwell, D. and Finch, R. (1999). End product quality and agronomic performance of compost. Compost Sci. Util., 7(2), 17-29.

Fennel, K., Losch, M., Schroter, J. and Wenzel, M. (2001). Testing a marine ecosystem model: sensitivity analysis and parameter optimization. J. Marine Syst., 28, 45-63.

Freeman, T.M. and Cawthon, D.L. (1999). Use of composted dairy solid biomass, poultry litter and municipal biosolids as greenhouse growth media. Compost Sci. Util., 7(3), 66-71.

Foust, A.S., Wenzel, L.A., Clump, C.V., Maus, L. and Anderson, L.B. (1980). Principles of Unit Operations, John Wiley \& Sons, New York.

Ghaly, A.E., Alkoaik, F. and Snow, A. (2006). Thermal balance of invessel composting of tomato plant residues. Can. Biosyst. Eng., $48,1-11$.

van Ginkel, G.T., Raats, P.A.C. and van Haneghem, I.A. (1999). Bulk density and porosity distributions in a compost pile. Netherlands J. Agric. Sci., 47, 105-121.

Hamby, D.M. (1994). A review of techniques for parameter sensitivity analysis of environmental models. Environ. Monit. Assess., 32(2), 135-154

Hassen, A., Belguith, K., Jedidi, N., Cherif, M. and Boudabous, A. (2002). Microbial characterization during composting of municipal solid waste, in Proc. of International Symposium on Environmental Pollution Control and Waste Management, Tunis (EPCOWM'2002), pp. 357-368.

Haug, R.T. (1993). The Practical Handbook of Compost Engineering, Lewis Publishers.

Helton, J.C. and Iman, R.L. (1982). Sensitivity analysis of a model for the environmental movement of radionuclides. Health Phys., $42,565-584$

Hess, T.F., Crdzelishvili, I., Sheng, H. and Hovde, C.J. (2004). Heat inactivation of $E$. Coli during manure composting. Compost Sci. Util., 12(4), 314-322.

Hogan J.A., Miller, F.C. and Finstein, M.S. (1989). Physical modeling of the composting ecosystem. Appl. Environ. Microbiol.-Am. Soc. Microbiol., 55(5), 1082-1092.

Hong, J.H. and Park, K.J. (2004). Wood chip biofilter performance of ammonia gas from composting manure. Compost Sci. Util., 12 (1), 25-30.

Hornberger, G.M. and Spear, R.C. (1980). An approach to the preliminary analysis of environmental system. J. Environ. Manage., 12, 7-18.

Iwabuchi, K. and Kamide, J. (1993). Simplified determination of thermal properties for moist and porous materials-measurement of thermal properties of compost. J. Jap. Soc. Agric. Mach., 55(3), 73-79.

Kaiser, J. (1996). Modeling composting as a microbial ecosystem: a simulation approach. Ecol. Model., 91, 25-37.

Komilis, P.D. (2004). A kinetic analysis of solid waste composting at optimal conditions. Waste Manage., 26, 82-91.

Korner, I., Brilsky, H., Jensen, U., Ritzkowski, M. and Stegmann, R. (1997). Possibilities for the Regulation of the Composting Process to Optimize the Nutrient Composition of Compost, International Conference, Harrogate, UK, ORBIT 97, pp. 211-219.

Lehmann, R.G., Smith, D.M., Narayan, R., Kozerski, G.E. and Miller, J.R. (1999). Life Cycle of silicone polymer, from pilot-scale composting to soil amendment. Compost Sci. Util., 7(3), 72-82.

Lemus, G.R. and Lau, A.K. (2002). Biodegradation of lipidic compounds in synthetic food wastes during composting. Can. Biosyst. Eng., 44, 33-39.

Liao, P.H., Vizcarra, A.T., Chen, A. and Lo, K.V. (1994). Composting of salmon farm mortalities with passive aeration. Compost Sci. Util., 2(4), 58-64. 
Liang. Y., Leonard, J.J., Feddes, J.J. and McGill, W.B. (2004). A simulation model of ammonia volatilization in composting. Trans. ASAE, 47(5), 1667-1680.

Lyberg, M.D. and Hogland, W. (2004). Performance of a vertically fed compost reactor. Compost Sci. Util., 12(2), 169-174.

MacGregor, S.T., Miller, F.C., Psarianos, K.M. and Finstein, M.S. (1981). Composting process control based on interaction between microbial heat and temperature. Appl. Environ. Microbiol., 41, 1321-1330.

Marugg, C., Grebus, M., Hansen, R.C., Keener, H.M. and Hoitink, H.A.J. (1993). A kinetic model of yard waste composting. Compost Sci. Util., 1(1), 38-51.

Mason, I.G. and Milke, M.W. (2005). Physical modeling of the composting environment: A review Part 1, Reactor systems. Waste Manage., 25, 481-500.

McCartney, D. and Chen, H. (2000). Physical Modeling of the composting environment: Determining the free airspace (FAS) and bulk density (BD) profiles of composting feedstock materials, in Proc. of the $10^{\text {th }}$ Annual Composting Council Conference, Edmonton, AB, Canada.

Mohee, R. and Mudhoo, A. (2005). Analysis of physical properties of an in-vessel composting matrix. Powder Technol., 155(1), 9299.

Mohee, R., White, R.K. and Das, K.C. (1998). Simulation model for composting of cellulosic (bagasse) substrates. Compost Sci. Util., $6(2), 82-92$

Nakasaki, K., Ohtaki, A., Sato, N. and Kubota, H. (1997). Effects of Temperature and Inoculum on the Degradability of Biodegradable Plastic during Composting, International Conference, Harrogate, UK, ORBIT97, pp. 205-208.

Narihiro, T. and Hiraishi, A. (2005). Microbiology of fed-batch composting. Microbes Environ., 20(1), 1-13.

Nielsen, H. and Berthelsen, L. (2002). A Model for temperature dependency of thermophilic composting process rate. Compost Sci. Util., 10(3), 249-257.

Parker, W.J. (1997). A multi-Parameter sensitivity analysis of a model describing the fate of volatile organic compounds in trickling filters. J. Air Waste Manage. Assoc., 47, 871-880.

Petiot, C. and de Guardia, A. (2004). Composting in a laboratory reactor: A review. Compost Sci. Util., 12(1), 69-79.

Proakis, G.J. (2000). Digital Communications, Fourth Edition. McGraw-Hill.

Rabinowitz, N. and Steinberg, D.M. (1991). Seismic hazard sensitivity analysis: a multi-parameter approach. Bull. Seis. Soc. Am., 81(3), 796-817.

Rahman, M.S. (1984). Microcalorimetric Measurement of Heat Production and Thermophysical Properties of Compost, Ph.D. Dissertation, Department of Biological and Agricultural Engineering, Rutgers University, New Jersey.

Ravalico, J.K., Maier, H.R., Dandy, G.C., Norton, J.P. and Croke, B.F.W. (2005). A comparison of sensitivity analysis techniques for complex models for environmental management, in Proc. of the MODSIM05 (Modeling \& Simulation Society of Australia \& New Zealand), Melbourne, Australia.
Raviv, M., Medina, S. and Shamir, Y. (1999). Cocomposting and method to improve results of poultry manure composting. Compost Sci. Util., 7(2), 70-73.

Richard, T.L., Hamelers, H.V.M., Veeken, A. and Silva, T. (2002). Moisture relationships in composting processes. Compost Sci. Util., 10(4), 286-302.

Richard, T.L., Veeken, A., de Wilde, V. and Hamelers, H.V.M. (2004). Air-filled porosity and permeability relationships during solidstate fermentation. Biotechnol. Prog., 20(5), 1372-1381.

Robinzon, R., Kimmel, E., Krasovitski, B. and Avnimelech, Y. (1999). Estimation of bulk parameters of a composting process in windrows. J. Agric. Eng. Res., 73, 113-121.

Rothbaum, H.P. (1960). Heat output of thermophiles occurring on wool. J. Bacteriol., 81(2), 165-171.

Saltelli, A., Tarantola, S. and Campolongo, F. (2000). Sensitivity analysis as an ingredient of modeling. Stat. Sci., 15(4), 377-395.

Sartaj, M., Fernandes, L. and Patni, N.K. (1997). Performance of forced, passive, and natural aeration methods for composting manure slurries. Trans. ASAE, 40(2), 457-463.

Seki, H. (1989). An investigation of practical process design and control of a soil warming system with heat generated in compost. J. Agric. Meteorol., 44(4), 259-267.

Stombaugh, D.P. and Nokes, S.E. (1996). Development of a biologically based aerobic composting simulation model. Trans. ASAE, 39, 239-250.

Taiwo, L.B. and Oso, B.A. (2004). Influence of the composting techniques on microbial succession, temperature and $\mathrm{pH}$ in a composting municipal solid waste. Afr. J. Biotechnol., 3(4), 239-243.

Tian, T. (2004). Robustness of mathematical models for biological systems. ANZIAM J., 45(E), 565-577.

Turanyi, T. (1990). Sensitivity analysis of complex kinetic systems: Tools and applications. J. Math. Chem., 5(3), 230-248.

VanderGheynst, J.S., Walker, L.P. and Parlange, J.Y. (1997). Energy transport in high-solids aerobic degradation process: Mathematical modeling and analysis. Biotechnol. Prog., 13, 238-248.

Veeken, A., Timmermans, J., Szanto, G. and Hamelers, B. (2003). Design of passively aerated compost systems on basis of compaction-porosity-permeability data, in Proc. of ORBIT 2003, Biological Processing of Organics, Perth, Australia, pp. 85-96.

Venelampi, O., Weeber, A., Ronkko, T. and Itavaara, M. (2003). The biodegradation and disintegration of paper products in the composting environment. Compost Sci. Util., 11(3), 200-209.

Vining, M.A. (2002). Bench-Scale Compost Reactors System and the Self-Heating Capabilities, M.Sc. Dissertation, B\&S Texas University.

Vuorinen, A.H. and Saharinen, M.H. (1999). Cattle and pig manure and peat cocomposting in a drum composting system-microbiological and chemical parameters. Compost Sci. Util., 7(3), 54-65.

Xi, B., Wei, Z. and Hongliang, L. (2005). Dynamic simulation for domestic solid waste composting process. The J. Am. Sci., 1(1), 34-45.

Yu, S., Clark, O.J. and Leonard, J.J. (2005). Airflow measurement in passively aerated compost. Can. Biosyst. Eng., 47, 39-45. 